\title{
Modeling of the Toxicity of Eucalyptus globulus Labill Essential Oil against Red Flour Beetle, Tribolium castaneum Herbst
}

\author{
*EBADOLLAHI, A; TAGHINEZHAD, E \\ Moghan College of Agriculture and Natural Resources, University of Mohaghegh Ardabili, Ardabil, Iran. \\ *Corresponding Author Email: ebadollahi@uma.ac.ir
}

\begin{abstract}
Although the application of synthetic chemicals is the main method in the management of insect pests, their overuse has led to public concerns about environmental pollution, threats to human health, and acute and chronic toxicity on non-target organisms. Plant essential oils have introduced as healthy, available, and effective alternatives to detrimental chemicals in recent years. Further, it is necessary to predict the exact amount of required pesticide to save costs and determine the optimal conditions for achievement to the best outcomes. Accordingly, the toxicity of Eucalyptus globulus Labill essential oil against the adults of a cosmopolitan pest Tribolium castaneum Herbst (red flour beetle) along with its modeling and optimization was assessed using Response Surface Methodology (RSM). The coefficients of the essential oil concentration and time as independent variables are positive, showing their increase results in the augmentation of insect pest mortality. E. globulus essential oil showed prospective concentration-time dependent fumigant toxicity against $T$. castaneum. A quadratic polynomial equation was achieved for the toxicity of $E$. globulus essential oil using multiple regression analysis: $7.33413+0.20191 \mathrm{~A}+0.47313 \mathrm{~B}+4.64054 \mathrm{E}-003 \mathrm{AB}+0.016349 \mathrm{~B}^{2}$, in which $\mathrm{A}$ and $\mathrm{B}$ are the exposure time and essential oil concentration. The accuracy of the introduced model was approved through the analysis of variance. Results of the optimization indicated that $45.50 \mu \mathrm{l} / \mathrm{l}$ of essential oil and $72.00 \mathrm{~h}$-exposure time would be adequate to achieve $92.45 \%$ mortality of $T$. castaneum. According to the results of current study, E. globulus essential oil has high potential in the management of T. castaneum and the Response Surface Methodology (RSM) is a suitable method to the optimization and modelling of this bio-effect.
\end{abstract}

DOI: https://dx.doi.org/10.4314/jasem.v24i12.5

Copyright: Copyright $(02020$ Ebadollahi and Taghinezhad. This is an open access article distributed under the Creative Commons Attribution License (CCL), which permits unrestricted use, distribution, and reproduction in any medium, provided the original work is properly cited.

Dates: Received: 17 October 2020; Revised: 23 November 2020; Accepted: 27 November 2020

Keywords: essential oil, fumigant toxicity, modelling, optimization, Response Surface Methodology

Tribolium castaneum Herbst (Coleoptera: Tenebrionidae), the red flour beetle, is one of the major stored-product insect pests throughout the world. The quantity of several products from animal and plant origins such as cereal grains, beans, flour, and leather was diminished by direct feeding of this pest. Further, the quality of foodstuffs has also greatly reduced by remains of insect skin after molting and by the benzoquinone compounds excreted from its abdominal glands (Li et al., 2013). It has also recently notified that $T$. castaneum can transfer some medically pathogenic microbes such as Pseudomonas, Staphylococcus, and Aspergillus (Prabha Kumari et al., 2011; Bosly and Kawanna, 2014). Chemical insecticides are widely used to protect agricultural products against insect pests but their overuse resulted in several worrying side-effects such as negative impacts on non-target organisms including fish, birds, and useful predators, parasitoids and pollinators' insects, contamination of groundwater, and their residues on foods and even in human breast milk (Shukla et al., 2006; Goulson, 2014; Reiler et al., 2015; Nicolopoulou-Stamati et al.,
2016). In this circumstance, the current agricultural strategies have to introduce environmentally safe tools to reduce the utilization of synthetic chemicals. The aromatic plant comprise essential oils as secondary metabolites which are responsible for their aroma and tolerance before phytophagous insect pests (Isman, 2006; Rajendran and Sriranjini, 2008). Essential oils, with low mammalian toxicity and eco-friendly biodegradation features, have been considered as potential fumigants against different groups of storedproduct insect pests (Pavela and Benelli, 2016; Walia et al., 2017). Although the plant essential oils have now been used to the insect pest management in the Asia, Africa, and USA for over a decade, and in the EU in the last 5 years (Isman, 2020), the outcomes for optimized conditions and the modeling of their insecticidal efficiency are absent now.

Response surface methodology (RSM) is based on combining mathematical and statistical techniques to set a polynomial equation for experimental findings. It can explain the performance of a response affected by several variables, evaluate the most effective factor on 
the selected response, create a model for prediction, and explore experimental conditions to the optimization (Riswanto et al., 2019; Chollom et al., 2020). Hence, RSM has been utilized in several recent agricultural, pharmacological, and chemical studies and related fields (Abdella et al., 2018; Kaur et al., 2018; Yoo et al., 2018; Ning and Yue, 2019). The goals of the present study can be categorized as 1) to evaluate the fumigant toxicity of the essential oil extracted from Eucalyptus globulus Labill against $T$. castaneum and 2) to find a mathematical model and optimized conditions for considered essential oil concentrations and exposure times in the mortality of insect pest by RSM.

\section{MATERIALS AND METHODS}

Essential oil: The essential oil of E. globulus, with the origin of Kazeron (Iran), was purchased from Barij Essence Company (Kashan, Isfahan Province, Iran).

Insect rearing: Parent adults of $T$. castaneum were achieved from stock cultures at the Universities of Urmia and Mohaghegh Ardabili, Iran. The insect was reared on wheat grains and flour in the separate glass containers covered by a fine mesh cloth for ventilation. Contaminated wheat grains and flour were separately maintained in the incubator with $27 \pm 2{ }^{\circ} \mathrm{C}$ and $60 \pm$ $5 \%$ RH in the dark (Arnaud et al., 2005). Synchronized adult insects with $1-14$ days-old were selected for fumigant bioassays.

Fumigant toxicity: The concentrations were poured on the $2 \times 2 \mathrm{~cm}$ filter paper (Whatman No. 1) which were attached to the inner surface of the screw cap of 340

$$
y=\beta o+\sum_{i=1}^{k} \beta_{i} X_{i}+\sum_{i=1}^{k} \beta_{j} X_{j}+\sum_{i=1}^{k} \sum_{j=1}^{k} \beta_{i j} X_{i} X_{j}+\sum_{i=1}^{k} \beta_{j j} X_{j}^{2}
$$

Where $y$ is the dependent variable (insect pest mortality), $X_{i}$ and $X_{j}$ are independent variables (time and essential oil concentrations, respectively), $\mathrm{k}$ is a number of independent variables, $\beta_{o}$ is intercept of the model, $\beta_{i}$ and $\beta_{j}$ are the coefficients of the linear parameters, and $\beta_{i j}$ indicate the coefficient of quadratic parameter. Correlation coefficients of determination $\left(\mathrm{R}^{2}\right)$, adjusted $R^{2}$, and predicted $R^{2}$ were used to estimate the relationship between the independent variables and responses.

\section{RESULTS AND DISCUSSION}

The results showed that the tested concentrations of essential oil had promising fumigant toxicity against the adults of $T$. castaneum. The interaction between essential oil concentrations and exposure times on the insect mortality is displayed in Figure 1, in which the $\mathrm{ml}$ glass containers as fumigant chambers. Twenty 114 days-old unsexed adults were put into glass containers and their caps was tightly screwed and to prevent air in and out sealed with parafilm. The fumigant chamber were then kept in the incubator with $27 \pm 2^{\circ} \mathrm{C}$ and $60 \pm 5 \% \mathrm{RH}$, and the mortality was documented after 24, 48 and $72 \mathrm{~h}$. Insects were considered dead when their antenna or legs did not move in contact with the brush. Same procedures were organized for control groups without adding essential oils' concentrations. Each treatment was replicated four times and mortality in the control group, if any, was corrected by the Abbott formula as follow; $P \mathrm{t}=$ $[(P \mathrm{o}-P \mathrm{c}) /(100-P \mathrm{c})] \times 100$, in which $P \mathrm{t}$ is the corrected mortality $(\%), P o$ is the mortality $(\%)$ of insects treated by essential oil concentrations and $P \mathrm{c}$ is the mortality (\%) of insects in the control groups.

Analysis using Response Surface Methodology (RSM): The historical data design used to assess the effects of independent variables (essential oil concentrations and exposure times) on the dependent variable (insect-pest mortality) utilizing the polynomial equation through RSM and the statistical software Design Expert 8.0.6 (Stat-Ease, Inc. USA). The independent factors essential oil concentrations $(\mu 1 / 1)$ and exposure times (h) had five and three levels, respectively, which were used in three replications. Analysis of variance (ANOVA) was also done to find the interactions between independent variables and responses using Design Expert software. The mathematical model between independent and dependent variables measured by multiple linear regression analysis in the following form:

mortality of insect pests was decreased by increasing the essential oil concentration and time. The plot of residuals versus predicted response was shown in Figure 2, indicating the introduced mortality model is proper for predicting the mortality of $T$. castaneum and consistent with the variation hypothesis. Analysis of variance indicated that $A$ (exposure time), $B$ (essential oil concentration), $\mathrm{AB}$, and $\mathrm{B}^{2}$ significantly $(\mathrm{P}<0.01)$ affected the mortality of $T$. castaneum. It can also be said that the greatest response mortality was obtained by the essential oil concentration factor in comparison with the exposure time (Table 1). Further, the lack of fit test was also found non-significant in table 1, representing the validation of treatment. For a welladjusted regression model, $\mathrm{R}^{2}$ values should be more than $80 \%$, which can found in the model presented in Table 2. The coefficients of the essential oil concentration and exposure time (independent 
variables) are positive, indicating an increase in each of them results in an extension of the insect pest mortality (response variable). The optimal response values before independent variables were determined by working on the regression equation announced in table 2 through the design expert software. The optimization conditions were obtained at concentration of E. globulus essential oil and exposure time for $92.45 \%$ mortality of $T$. castaneum are 45.50 $\mu \mathrm{l} / 1$ and $72.00 \mathrm{~h}$, respectively, according to table 3 . To achieve $50 \%$ mortality of $T$. castaneum, the $36.40 \mathrm{~h}-$ exposure times, and $30.82 \mu 1 / 1$ essential oil concentration would be adequate (Table 3 ).
The fumigant toxicity of E. globulus essential oil was approved against some stored-product insect pests such as the cigarette beetle [Lasioderma serricorne F. (Coleoptera: Anobiidae)], the lesser grain borer [Rhyzopertha dominica F. (Coleoptera: Bostrichidae)], the maize weevil [Sitophilus zeamais Mots (Coleoptera: Curculionidae)], and the saw-toothed beetle [Oryzaephilus surinamensis (L.) (Coleoptera: Silvanidae)] (Ebadollahi et al., 2010; Abd El-Salam et al., 2019; Araújo et al., 2019). Although results of these studies are in parallel with our findings about the insecticidal efficiency of $E$. globulus essential oils, the optimization and modeling of its insecticidal effects were reported for the first time in the present study.

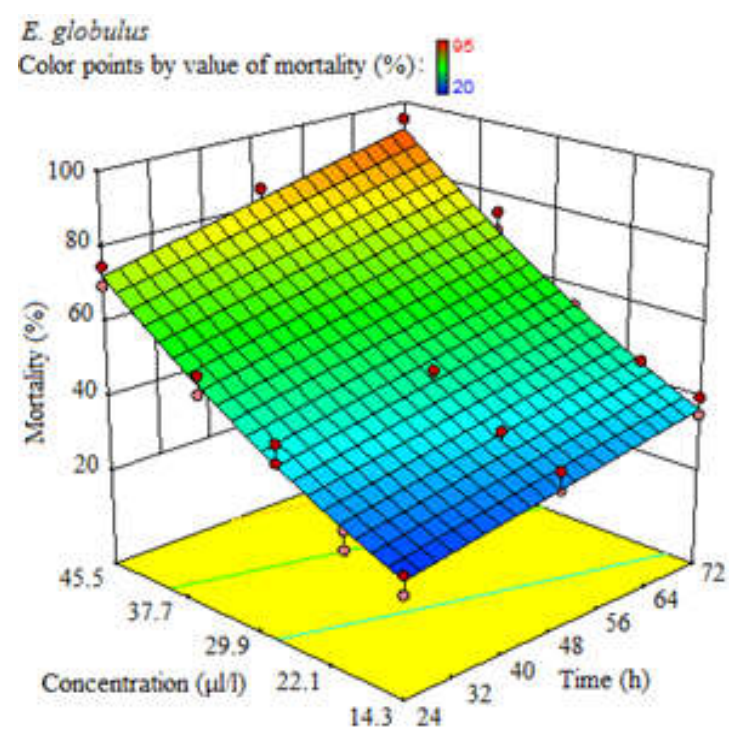

Fig. 1: Three-dimensional diagrams of the mortality of T. castaneum caused by the fumigation of E. globulus essential oil.

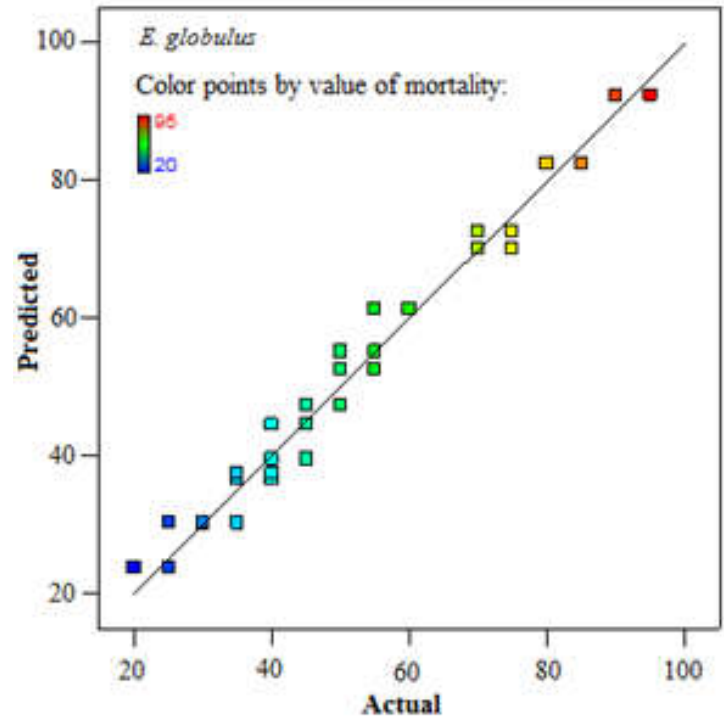

Fig. 2: Plot of residual versus predicted mortality of $T$. castaneum caused by the fumigation of $E$. globulus essential oil. EBADOLLAHI, A; TAGHINEZHAD, E 
Table 1: Results of analysis of variance for prediction of the fumigant toxicity of E. globulus essential oil against T. castaneum

\begin{tabular}{llllll}
\hline Source & $\begin{array}{l}\text { Sum of } \\
\text { Squares }\end{array}$ & df & $\begin{array}{l}\text { Mean } \\
\text { Square }\end{array}$ & F value & p-value \\
\hline Model & 23291.04 & 4 & 5822.76 & 631.30 & $<0.0001$ \\
$\mathrm{~A}$ & 2620.06 & 1 & 2620.06 & 284.06 & $<0.0001$ \\
$\mathrm{~B}$ & 20422.13 & 1 & 20422.13 & 2214.14 & $<0.0001$ \\
$\mathrm{AB}$ & 60.32 & 1 & 60.32 & 6.54 & 0.0133 \\
$\mathrm{~B}^{2}$ & 166.27 & 1 & 166.27 & 18.03 & $<0.0001$ \\
Residual & 507.29 & 55 & 9.22 & & \\
Lack of Fit & 157.29 & 10 & 15.73 & 2.02 & $0.0531^{\mathrm{NS}}$ \\
Pure Error & 350.00 & 45 & 7.78 & & \\
Cor Total & 23798.33 & 59 & & & \\
\hline
\end{tabular}

A and $B$ are the exposure time $(h)$ and essential oil concentrations $(\mu 1 / 1)$, respectively. NS: Non-Significant.

Table 2: Estimated regression model of the fumigant toxicity of $E$. globulus essential oil against $T$. castaneum

\begin{tabular}{ccccc}
\hline Equation & $\boldsymbol{R}^{2}$ value & Adj $\boldsymbol{R}^{2}$ & Pred $\boldsymbol{R}^{2}$ & C.V. (\%) \\
\hline $7.33413+0.20191 \mathrm{~A}+0.47313 \mathrm{~B}+4.64054 \mathrm{E}-003 \mathrm{AB}+0.016349 \mathrm{~B}^{2}$ & 0.9787 & 0.9771 & 0.9747 & 5.86
\end{tabular}

$\mathrm{A}$ and $\mathrm{B}$ are actual factors for exposure time $(\mathrm{h})$ and essential oil concentrations $(\mu \mathrm{l} / \mathrm{l})$, respectively. Response variable is mortality percentage.

Table 3: Optimization of the mortality of T. castaneum caused by the fumigation of E. globulus oil

\begin{tabular}{llll}
\hline Mortality (\%) & Time $(\mathbf{h})$ & Concentration $(\boldsymbol{\mu l} / \mathbf{l})$ & Desirability \\
\hline 50.000 & 36.399 & 30.819 & 1.000 \\
$92.449^{*}$ & 72.000 & 45.500 & 0.966
\end{tabular}

*The maximum significant mortality percentage based on high desriability calculated by Desighn Expert Sofftware.

The use of RSM for modeling and optimization of the insecticidal properties of plant essential oils had been reported in a few recent studies. Regarding the fumigant toxicity of the essential oil of Thymus kotschyanus Boiss. \& Hohen against $R$. dominica (Ebadollahi, 2018), and based on the high coefficient of variation value $(8.02 \%)$, it was find that the presented model " $52.08+3.49 \mathrm{~B}+22.84 \mathrm{~A}-1.72 \mathrm{AB}-$ $2.06 \mathrm{~A}^{2}+3.73 \mathrm{AB}^{2}-5.60 \mathrm{~A}^{3}$ " was the best for estimating the effects of independent variables (concentration (A) and time (B)) on the insect pest mortality. The negative signs were also showed the diminishing effect of the variables on the insect mortality. Further, optimization of the fumigant toxicity revealed that a concentration of $24.62 \mu 1 / 1$ and $57.98 \mathrm{~h}$-exposure time was sufficient to kill $50 \%$ of tested insect population (Ebadollahi, 2018). In other study, modeling and optimization of the insecticidal activities of the essential oil extracted from Teucrium polium L. against $T$. castaneum was assessed by RSM. The "+0.71- 0.047A - 8.84E-3B + $3.89 \mathrm{E}-4 \mathrm{AB}+3.27 \mathrm{E}-3 \mathrm{~A}^{2}+8.38 \mathrm{E}-5 \mathrm{~B}^{21}$ was introduced as the best model for predicting the essential oil' concentration (A) and exposure time (B) effects on the mortality of $T$. castaneum. The optimal condition for reaching maximum mortality $(97.97 \%)$ was $20 \mu \mathrm{l} / 1$ essential oil concentration and 72 min-exposure time (Ebadollahi and Taghinezhad, 2020). Along with insecticidal effects, the modeling and optimization of antifungal activity of the plant-derived essential oil was also performed by the RSM (Ebadollahi et al., 2018).

Conclusion: Several side effects of synthetic pesticides, such as environmental pollution, the threat to human health, pest resistance, and the harmful effects on beneficial organisms, necessitate the use of low-risk and efficient alternatives. In this regard, in recent years, the use of plant-derived essential oils to manage insect pests has been recommended by many studies. Therefore, in the present study, the possibility of controlling $T$. castanem adults by the essential oil of E. globulus was investigated and approved. Further, due to the need to determine the optimal amount of pesticides to prevent cost increases and to predict pest losses, optimization and modeling of observed fumigant toxicity was also performed using RSM. The best regression model for toxicity was obtained a quadratic equation, and optimal conditions for $92.45 \%$ mortality of $T$. castaneum were $45.50 \mu \mathrm{l} / 1$ of $E$. globulus essential oil and $72.00 \mathrm{~h}$-exposure time.

\section{REFERENCES}

Abd El-Salam, AME; Abd elwahed Salem, S; AbdelRahman, RS (2019). Fumigant and toxic activity of some aromatic oils for protecting dry dates from Oryzaephilus surinamensis (L.) (Coleoptera: Silvanidae) in stores. Bull. Natl. Res. Cent. 43: 63.

Abdella, A; El baz, AF; Mahrous, EE; El Maksoud, AAA; Ibrahim, IA; Abdel-Monem, AR; Yang, ST. (2018). Response surface methodology for optimization of genistein content in soy flour and its effect on the antioxidant activity. Iran J. Pharm. Res. 17: 10261035.

Araújo, AMN; Oliveira, JV; França, SM; Navarro, DMAF; Barbosa, DRS; Dutra, KA (2019). Toxicity and repellency of essential oils in the management of 
Sitophilus zeamais. R. Bras. Eng. Agric. Ambiental. 23(5): 372-377.

Arnaud, L; Brostaux, Y; Lallemand, S; Haubruge, E (2005). Reproductive strategies of Tribolium flour beetles. J. Insect Sci. 5: 33.

Bosly, HAQ; Kawanna, MA (2014). Fungi species and red flour beetle in stored wheat flour under Jazan region conditions. Toxicol. Ind. Health. 30: 304-310.

Ebadollahi, A (2018). The essential oil extracted from Thymus kotschyanus Boiss. \& Hohen as a natural substance for management of the lesser grain borer, Rhyzopertha dominica F. Agric. For. 64(4): 490495.

Ebadollahi, A; Safaralizadeh, MH; Pourmirza, AA (2010). Fumigant toxicity of essential oils of Eucalyptus globulus Labill and Lavandula stoechas L. grown in Iran, against the two coleopteran insect pests; Lasioderma serricorne F. and Rhyzopertha dominica F. Egypt. J. Biol. Pest Cont. 20 (1): 1-5.

Ebadollahi, A; Taghinezhad, E (2020). Modeling and optimization of the insecticidal effects of Teucrium polium L. essential oil against red flour beetle (Tribolium castaneum Herbst) using response surface methodology. Inf. Process. Agric. 7(2): 286293.

Ebadollahi, A; Taghinezhad, E; Davari, M (2018). Optimization of the antifungal activity of essential oil isolated from aerial parts of Thymus kotschyanus Boiss \& Hohen (Lamiaceae). J. Appl. Sci. Environ. Manage. 22 (6): 907-910.

Goulson, D (2014). Ecology: pesticides linked to bird declines. Nature. 511: 295-296.

Isman, MB (2006). Botanical insecticides, deterrents, and repellents in modern agriculture and an increasingly regulated world. Annu. Rev. Entomol. 51: 45-66.

Isman, MB (2020). Commercial development of plant essential oils and their constituents as active ingredients in bioinsecticides. Phytochem Rev. 19: 235-241.

Kaur, G; Kumar, V; Goyal, A; Tanwar, B; Kaur, J (2018). Optimization of nutritional beverage developed from radish, sugarcane and herbal extract using response surface methodology. Nutr. Food Sci. 48(5): 733743.

Li, J; Lehmann, S; Weißbecker B, Naharros, IO; Schütz, S; Joop, G; Wimmer, EA (2013). Odoriferous defensive stink gland transcriptome to identify novel genes necessary for quinone synthesis in the red flour beetle, Tribolium castaneum. PLoS Genet. 9: 1003596.

Nicolopoulou-Stamati, P; Maipas, S; Kotampasi, C; Stamatis, P; Hens, L (2016). Chemical pesticides and human health: the urgent need for a new concept in agriculture. Front. Public Health. 4: 148.

Ning, J; Yue, S (2019). Optimization of preparation conditions of eucalyptus essential oil microcapsules by response surface methodology. J. Food Process. Preserv. 43: 14188.

Pavela, R; Benelli, G (2016). Essential oils as ecofriendly biopesticides? Challenges and constraints. Trends Plant Sci. 21: 1000-1007.

Prabha Kumari, C; Sivadasan, R; Jose, A (2011). Microflora associated with the red flour beetle, Tribolium castaneum (Coleoptera: Tenebrionidae). J. Agr. Technol. 7: 1625-1631.

Rajendran, S; Sriranjini, V (2008). Plant products as fumigants for stored product insect control. J. Stored Prod. Res. 44: 126-135.

Reiler, E; Jørs, E; Bælum, J; Huici, O; Alvarez Caero, MM; Cedergreen, N (2015). The influence of tomato processing on residues of organochlorine and organophosphate insecticides and their associated dietary risk. Sci. Total Environ. 528: 262-269.

Riswanto, FDO; Rohman, A; Pramono, S; Martono, S (2019). Application of response surface methodology as mathematical and statistical tools in natural product research. J. Appl. Pharm. Sci. 9(10): 125-133.

Shukla, G; Kumar, A; Bhanti, M; Joseph, PE; Taneja, A (2006). Organochlorine pesticide contamination of ground water in the city of Hyderabad. Environ. Int. 32: $244-247$.

Walia, S; Saha, S; Tripathi, V; Sharma, KK (2017). Phytochemical biopesticides: some recent developments. Phytochem. Rev. 16: 989-1007.

Yoo, G; Lee, IK; Park, S; Kim, N; Park, J; Kim, S (2018). Optimization of extraction conditions for phenolic acids from the leaves of Melissa officinalis L. using response surface methodology. Pharmacogn. Mag. 14(54): 155-161.

\section{EBADOLLAHI, A; TAGHINEZHAD, E}

